\title{
An Application of Antifriction Coatings to Increase the Lifetime of Friction Units
}

\author{
Aleksandr $V$. Antsupov $^{1, *}$, Artem A. Fedulov ${ }^{2}$, Alexey V. Antsupov ${ }^{3}$, and \\ Victor P. Antsupov ${ }^{3}$ \\ ${ }^{1}$ Bauman Moscow State Technical University, 1050055 2nd Baumanskaya street, Moscow, Russia \\ ${ }^{2}$ Ural Federal University, 62000219 Mira street, Yekaterinburg, Russia \\ ${ }^{3}$ Magnitogorsk State Technical University, 45500038 Lenin street, Magnitogorsk, Chelyabinsk \\ Region, Russia
}

\begin{abstract}
This article presents a generalization of the results of theoretical and experimental studies on increasing the reliability of friction units by making antifriction coatings on the working surfaces with a flexible tool. The principle scheme and the essence of the method of cladding with a flexible tool (CFT) - shock-frictional forming of thin films from various materials on the surface of the workpiece with flexible elements of rotating metal brushes are described. Versions of cladding machinery and many parts of movable joints with various forms of friction surfaces, on which various metal, polymer, single and two-layer antifriction coatings are applied, are presented. The modification of the frictional application of polymer coatings is shown. The following is a brief description of the most significant effective results for increasing the durability of the industrial sliding friction and rolling friction units.
\end{abstract}

\section{The basics about the method and devices for cladding of surfaces with a flexible tool}

The method of shock-friction cladding with a flexible tool (SFC or CFT) of surfaces of various products is based on the idea of works [1-3]. It represents a certain type of shockfriction surface treatment with flexible wire elements of a rotating metal brush with the simultaneous deposition of thin films of various materials on them. The method was reproduced in the inventor's certificate [4] and found new practical application at the Magnitogorsk Mining and Metallurgical Institute in the 1990s. A group of scientists led by L.S. Belevsky tried to use it to apply an aluminium sublayer in the production of steelaluminium wire [5-7]. A detailed history of the development in different areas of research with a usage of this method is considered in works [7, 8, etc.]. The authors of this article took part in the formation and development of one of the directions - cladding of the working surfaces of various friction units to increase their durability [9-16, etc.]. A summary of the most effective practical results of these studies is presented in this publication.

\footnotetext{
* Corresponding author: antsupov.alexander@gmail.com
} 
The coating generation mechanism can be explained as follows (see Fig. 1.a). When part 1 and cladding tool 2 rotate, its flexible elements 3 come into contact with the surface of part 1 and ingot 4 . They transfer particles of ingot 4 melted by friction from its end to the surface of part 1 , cleaned of oxides and contaminants. the contact surface of the part is formed by a thin, firmly adhered to the base, coating film 5 [14]. When the tool 2 moves in the axial direction, a thin coating film 5, firmly adhered to the base, is formed on the entire contact surface of the part [14].

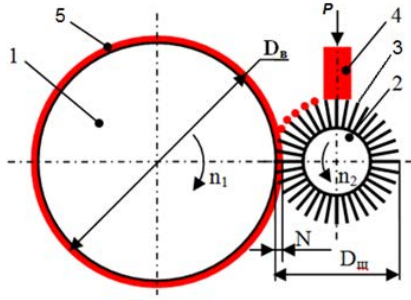

a

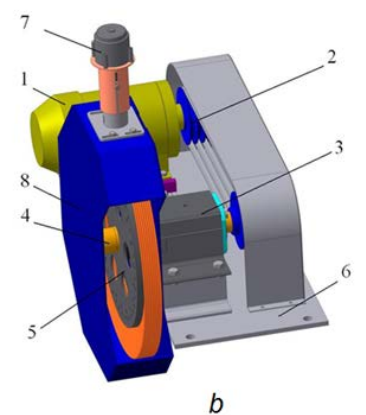

$b$

Fig. 1. The principle scheme (a) and the attachment (b) to machines for cladding the cylindrical parts.

Fig. 1b shows the simplest and most technologically advanced version of an industrial attachment to metal-cutting machines of the first group of the sixth type. The installation includes the following main components: electric motor 1; V-belt transmission 2; bearing unit 3 of the drive shaft 4 ; cladding tool 5 in a protective casing 8 ; unit for pressing the ingot to the brush 7 . The listed elements are fixed on the base 8 .

A number of industrial installations and devices for cladding the special, including large-sized, products of machine-building and metallurgical production, are shown in Fig. 2.
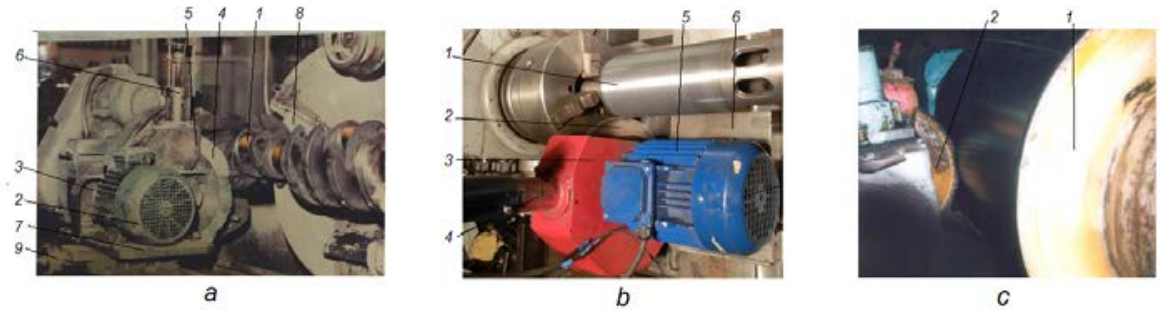

Fig. 2. Industrial cladding attachments for various metal-cutting machines.

Fig. 2.a shows an industrial installation for copper plating of crankshaft journals 1 of imported special equipment, which is being restored at the repair enterprises of the "Tyumenneftegaz" industrial association. It includes: electric motor 2; V-belt transmission 3 ; cladding tool 4 in a protective casing 5; unit for pressing the ingot to the brush 6 . All units are fixed on the base 7 , which is mounted on a movable wheel frame. In the working position, the installation rolls up to the grinding machine and is rigidly attached to its front surface with special clamps (not shown in Fig. 2.a). The brush 4 is installed strictly opposite to the grinding wheel 8 . The movement of the tool 4 and the provision of the specified interference $N$ (see Fig. 1.a) is carried out with the help of the feeder 9. Cladding of each neck with the tool 4 is performed immediately after the operation of their grinding with the wheel 8 . After that another neck is brought in and the "grinding-cladding" operation is repeated. 
The feature of the attachment to the lathe 16K20 (see Fig. 2.b) for cladding cylindrical parts 1 is the absence of a belt drive. The cladding tool 2 is fixed on the motor shaft 5 . All elements: the assembled brush 2, the casing 3 with the ingot feeding unit 4 and the motor 5 are mounted on the base 6 , which is fixed instead of the machine cutting tool holder.

The main difference between the device for applying polymer coatings on large-size rolling dies 1 (see Fig. 2.c) is that the assembled cladding tool 2 is fixed instead of the abrasive wheel of a roll grinder. The ingot feeding unit is traditionally mounted on the casing (not shown in Fig. 2, c). The cladding of the rolling roll is final (finishing) operation and is performed after its grinding. The monograph [14] describes a number of similar metalworking machines, converted for cladding flat and cylindrical surfaces.

\section{Possibilities, features and prospects of the CFT method}

The gathered operating experience and the results of known studies have shown that with the help of CFT it is possible to form coatings for various functional purposes: antifriction, corrosion-resistant, heat-resistant, anti-seizure, conductive, decorative, etc. Aluminium, copper, zinc, tin, lead, their alloys and compositions are widely used as coating materials. The average layer thickness of various coatings depending on the type of applied material is within the range of $0.5 \ldots 50$ microns. The experience in parts machining on mechanical equipment shows that the cladding speed is $0.1 \ldots 1.0 \mathrm{~m} 2 / \mathrm{s}$ with a thickness of up to 100 microns. The depth of the hardened base layer under the coating for the currently used processing modes in the annealed or normalized conditions does not exceed $30 \ldots 50$ microns. The thickness, composition, structure, character of adhesion and depth of the layer hardening depend on the treatment, properties of the coating and the base materials. However, the general characteristics of this method of application are strong adhesion to the base, the absence of preliminary and subsequent surface treatment [14].

The first feature of the CFT method was the possibility of sequential application of coatings from different materials in an acceptable order, i.e. to create multilayer coatings, as well as multicomponent from the appropriate complex ingots, which is extremely difficult to implement using known methods.

Secondly, laboratory studies have shown that, in addition to the formation of metal films on metal surfaces of various shapes, it is possible to apply coatings of non-ferrous metals on some non-metal products made of glass, ceramics, semi-precious minerals, tiles (Fig. 3, a). The first samples with wear-free ceramic coatings (of the corundum type) were obtained. Such super-hard oxidized films were obtained by combining the cladding process with plasma electrolytic oxidation (PEO) of the surface layer (Fig. 3, b).
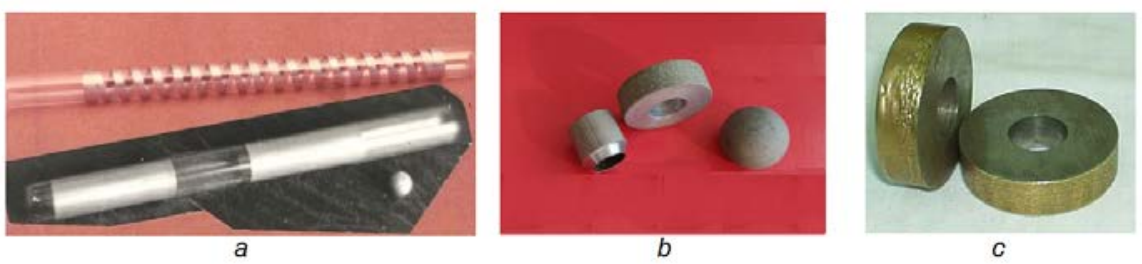

Fig. 3. Conductive layers (a) on the surface of glass products, (b) corundum coatings after CFT + PEO, (c) oil-absorbing coatings with a thickness of $500 \ldots 1000$ microns

Thirdly, cladding modes have been developed to obtain metal coatings of significant thickness (500 ... 1000 microns) with pores to increase the oil absorption of the surface layer (Fig. 3, c).

With the CFT method, it turned out to make it possible to clad metal surfaces with polymeric materials, in particular, with various grades of polytetrafluoroethylene 
(fluoroplastic) (see Figure 2, c). However, studies of surfaces after the "polymer" cladding showed that there is no continuous PTFE film: the coating material fills only the microrelief cavities. Nevertheless, the efficiency of such porous coating in a number of cases is relatively enough, especially after its secondary application on a metallic copper-bearing coating. In addition, this idea and its effect were used in the design of the durable friction units, when the surface layer of one of the parts is filled with inserts from this polymer (see Fig. 4), and an anti-friction coating is formed in the process of rubbing the surfaces. The efficiency of this upgrade is shown in the next section.
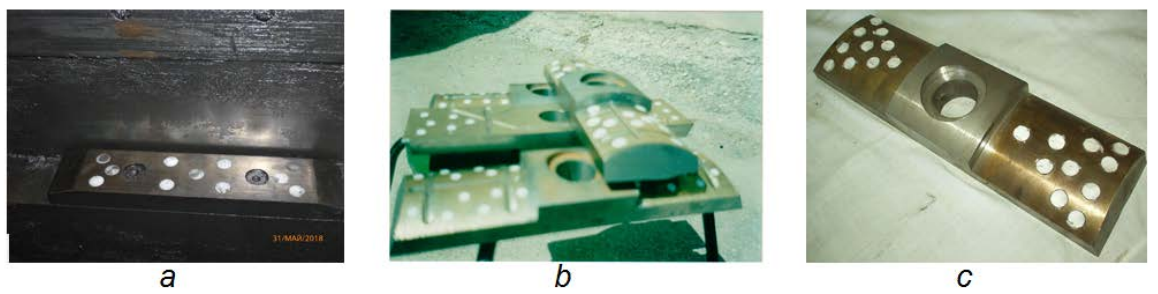

Fig. 4. Details of friction units with polymer inserts: (a) bronze sliding strips of roll chocks with F4 inserts, (b) brass liners of universal joints with PTFE inserts, (c) the steel liner with brass coating and polymer inserts

On the basis of a comparative analysis of the CFT method with functionally similar methods of coating application, it was established [14] that the cladding method is quite competitive from all technical and economic points of view. Its energy consumption, metal consumption, labor intensity and the cost of processing a specific value of surface are significantly lower than the corresponding indicators of electrolytic processes, surfacing and spraying, which proves the technical and economic feasibility of using CFT.

Positive results in improving the performance of a wide variety of products using CFT allowed formulating promising directions for its effective use [14]:

- increasing the durability of sliding and rolling friction units by applying copper-bearing and polymer coatings;

- extending the resource of friction units by restoring the size of worn parts and their operational properties;

- increasing the corrosion resistance of various metal products;

- increasing the reliability of long-term junctions by applying anti-seize coatings;

- obtaining long products with protective coatings for various purposes;

- applying conductive and colored decorative coatings on products made of non-metallic materials;

- obtaining ceramic wear-free coatings with simultaneous oxidation of aluminumcontaining layers, etc.

Practice has shown that the most demanded were the first two directions, and therefore the most striking examples of increasing the durability of movable interfaces of various machines and units are considered below.

\section{Increasing the lifetime of friction units using CFT}

Efficient cladding technologies for critical or unreliable friction units were designed within the framework of a general methodological approach to predicting and ensuring the reliability of machine parts $[15,16]$ and elements of friction units $[17,18]$ based on:

- the kinetic equation of friction surfaces wear, obtained by the combined solution of the basic equations of the molecular-mechanical and thermodynamic theory of friction [18]; 
- mathematical models of physical processes in the contact zones of flexible elements 3 with ingot 4 and part 1 , as well as the process of changing the properties of the surface layer [14].

- numerous results of laboratory tests of standard samples from various materials on a friction machine according to the "roller-block" scheme [17].

The most significant created to date is the technology of cladding details of sliding and rolling friction units tested in industrial conditions at various domestic and foreign enterprises (shown in Fig. 5-8) [14, 17].

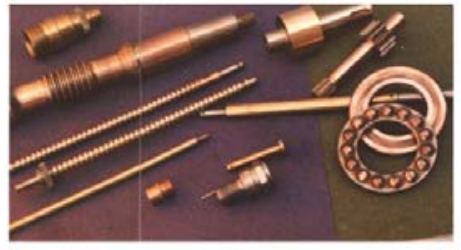

$a$

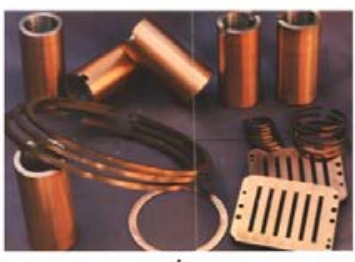

$b$

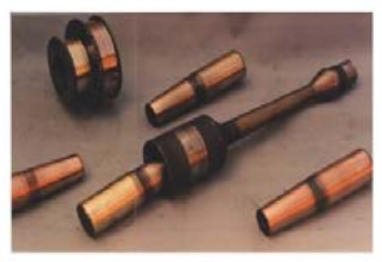

$c$

Fig. 5. Parts of sliding, rolling friction and lead screws (a) with copper plating, (b) copper-plated parts of compressor frames, (c) parts of vibrating bell for concrete shrinkage with copper plating

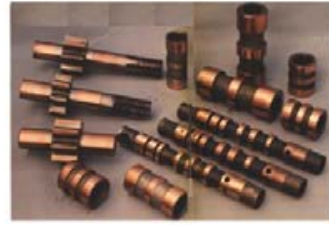

a

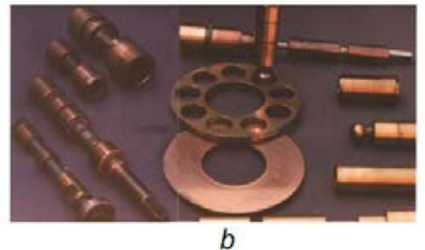

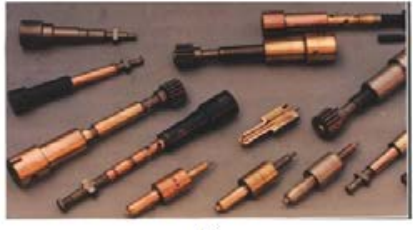

c

Fig. 6. Details of (a) hydraulic, (b) pneumatic and (c) fuel equipment with copper coatings

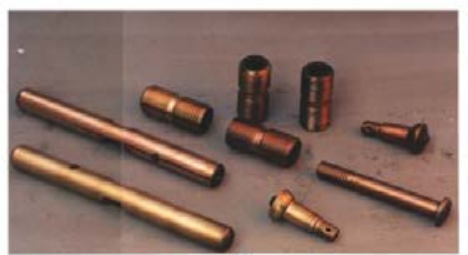

a

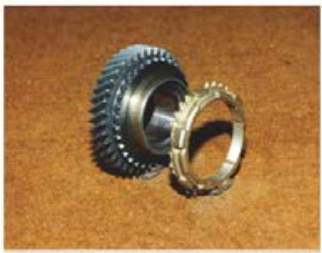

$b$

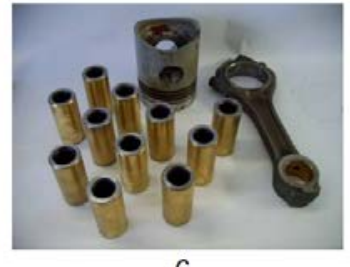

$c$

Fig. 7. Copper-plated and brass-plated parts of the threaded connections of (a) the front axle suspension of GAZ-24 vehicles, parts of (b) the gear stand synchronizer for VAZ vehicles with a brass coating, (c) piston pins of Belaz vehicles with a brass coating

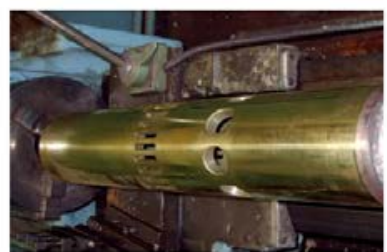

a

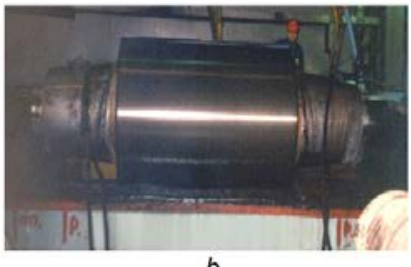

$b$

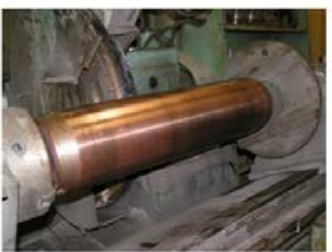

$c$

Fig. 8. Cylindrical parts treated with the CAE application (a) the brass-plated spool valves for descaling the surface of hot-rolled strips, (b) supporting rolls with polymer coating of the quarto stand of hot rolling sheet mills, (c) copper-plated plunger for hydraulic cylinders of the roll balancing system (c) 


\section{Conclusion}

The most significant quantitative results of the effective use of the method of shock-friction cladding are listed below: (for increasing the lifetime of sliding friction units [14])

- the pillow-blocks of hot-rolled rolls - $3.0 \ldots 8.0$ times.

- the bearings of rollers of KHP spare conveyors - $5.0 \ldots 6.0$ times.

- the bearing of rollers of CCM sections - $1.5 \ldots 2.0$ times.

- the liners of universal spindles of the hot rolling mill - $4.3 \ldots 6.0$ times.

- the inserts of the universal spindles of the cold rolling mill - $1.2 \ldots 1.5$ times.

- the key of the gear spindles of the cold rolling mill - $2.0 \ldots 2.5$ times.

- the fixing rods for the chocks of the cold rolling mill - $2.0 \ldots 2.5$ times.

- hydraulic cylinders for balancing the working rolls of the hot rolling mill - $1.7 \ldots 2.0$ times.

- hydraulic cylinders of the leveling beams of the supporting roll chocks of the cold rolling mill - 3 times.

- the plunger-gates of water descaling devices for hot rolling mills - $2.0 \ldots 2.5$ times.

- VAZ car gearstand synchronizers - 1.5 ... 1.65 times.

- the threaded pins of the suspension of GAZ 24-31105 - $1.4 \ldots 3.0$ times.

- the sliding bearings of the undercarriage of crawler excavators - 1.5 times.

- the bronze strips of rolling chocks sliding - 3-4 times.

(for increasing the durability of rolling friction units [14])

- by cladding the raceways of the inner rings of the bearings - $1.5 \ldots 2.0$ times.

- the rolling dies of a 20 -roll mill - 3.0 ... 5.0 times.

- supporting rolls of a hot sheet rolling mill - $1.4 \ldots 2.0$ times.

The presented results are recorded in the acts of implementation and protocols of industrial tests. The developed cladding technologies and new designs of modified units and parts are protected by patents for inventions and useful models.

\section{References}

1. Certificate of Authorship 57162 (USSR), A.A. Abinder, 6, 1-4 (1940)

2. Certificate of Authorship 139892 (USSR), I.M. Smirnov, N.A. Nikolaev, S.D. Krylov, 14, 59 (1961)

3. Patent 863087 (Great Britain), A.D. James, 3, 128 (1961)

4. Certificate of Authorship 1206068 (USSR) B 24 B 39 / 00, L.S. Belevsky, V.I. Kadoshnikov, Yu.V. Mironov, I.D. Kadoshnikova, 3, 3 (23.01.86)

5. G.B. Buhinik, L.S. Belevsky, V.I. Kadoshnikov, The theory and practice of hardware, Sverdlovsk, 29-33 (1987)

6. V.I. Kadoshnikov, Improving the technology of the bimetal steel-aluminium wire production by the new method of interlayer application, (Ph.D. thesis, Magnitogorsk, 1988)

7. L.S. Belevsky, Plastic deformation of a surface layer and generation of coating with the application of the flexible tool (College of the Academy of Science, Magnitogorsk, 1996)

8. L.S. Belevsky, R.R. Dema, M.A. Levantsevich, etc., Mechanical equipment of metallurgical plants (ed. A.G. Korchunov), 67-73, 2012

9. Patent 1590354 (Russia), V.P. Antsupov, L.S. Belevsky, V.A. Dosmanov, V.I. Kadoshnikov, 33, 66-67 (1990) 
10. L. Belevsky, V. Popov, S. Tulupov, O. Smirnov, Advanced Materials Research, 59, 4650 (2009)

11. A.N. Zavalischin, O.M. Smirnov, S.A. Tulupov, The modification of surface of metal products with coating (Moscow, Orbita-M, 2012)

12. V.L. Basinyk, M.A. Levantsevich, N.N. Maksimchenko, E.I. Mardosevich, Friction and wear, 34, 6, 575-582 (2013)

13. M.A. Levantsevich, N.N. Maksimchenko, Strengthening technologies and coatings, 10 (130), 16-20 (2015)

14. V V.P. Antsupov, The theory and practice of cladding products with the flexible tool (Magnitogorsk, MSTU, 1999)

15. A.V. Antsupov (jr), A.V. Antsupov, V.P. Antsupov, Estimation and Assurance of Machine Component Design. (Procedia Engineering), 150, 726-733 (2016)

16. A.V. Antsupov (jr), A.V. Antsupov, V.P. Antsupov, Steel in Translation, 60, 1, 30-35 (2017)

17. A.V. Antsupov (jr), A.V. Antsupov, V.P. Antsupov, The reliability provision of the friction units of machines (Magnitogorsk, MSTU, 2013)

18. A.V. Antsupov (jr), A.V. Antsupov, V.P. Antsupov, Friction and wear, 37, 5, 510-516 (2016) 